\title{
Inventory Modeling for Deteriorating Imperfect Quality Items with Selling Price Dependent Demand and Shortage Backordering under Credit Financing
}

\author{
Aditi Khanna ${ }^{1}$, Prerna Gautam², Chandra K. Jaggi ${ }^{3}$ \\ Department of Operational Research, Faculty of Mathematical Sciences \\ New Academic Block, University of Delhi \\ Delhi-110007, India \\ 11d.aditikhanna.or@gmail.com, ${ }^{2}$ prerna3080@gmail.com, ${ }^{3}$ ckjaggi@yahoo.com \\ ${ }^{*}$ Corresponding author
}

(Received November 11, 2016; Accepted December 31, 2016)

\begin{abstract}
The production processes throughout the world aim at improving quality by introducing latest technologies so as to perform well in fierce competition. Despite this due to various unavoidable factors, most of the manufacturing processes end up with certain imperfections. Hence, all the items produced are not of perfect quality. The condition tends to be more susceptible while dealing with items of deteriorating quality; therefore an inspection process is must for screening good quality items from the ordered lot. Demand is assumed to be price dependent and it is represented by a constant price elasticity function. Also to endure with the rapid growth and turbulent markets, the suppliers try to engage and attract retailers through various gimmicks and one such contrivance is offering trade credit, which is proved to be an influential strategy for attracting new customers. In view of this, the present paper develops an inventory model for items of imperfect quality with deterioration under trade-credit policies with price dependent demand. Shortages are allowed and fully backlogged. A mathematical model is developed to depict this scenario. The aim of the study is to optimize the optimal order level, backorder level and selling price so as to maximize the retailer's total profit. Findings are validated quantitatively by using numerical analysis. Sensitivity analysis is also performed so as to cater some important decisionmaking insights.
\end{abstract}

Keywords: Imperfect quality items, Deterioration, Shortages, Price-dependent demand, Credit financing.

\section{Introduction}

The traditional economic order quantity (EOQ) models have assumed implicitly that items are of perfect quality. Such an approach is superficial because in reality it is not justified to presume that items ordered or produced are flawless. Hence, several scholars came up with numerous practical EOQ models, with the assumption that items are not always conforming. Substantial amount of pioneer work in the same category has been done by the following authors; Porteus (1986) studied the effect of defectives on the basic EOQ model. Rosenblatt and Lee (1986) developed an inventory model for imperfect production system in which the time elapsed between the in-control and the out-of-control state follows an exponential distribution and the defectives are reworked instantaneously. Lee and Rosenblatt (1987) determined production cycle and maintenance by inspection policies for an inventory model. Salameh and Jaber (2000) developed an economic production quantity model for items of imperfect quality. Papachristos and Konstantaras (2006) investigated the problem of non-shortages with proportional imperfect quality, when the proportion of the imperfect items is considered to be a random variable. Maddah and Jaber (2008) rectified a flaw in Salameh and Jaber (2000) which led to simple expressions of the optimal order quantity and expected total profit per unit time. Maddah et al. (2010) considered an inventory system within 
International Journal of Mathematical, Engineering and Management Sciences

Vol. 2, No. 2, 110-124, 2017

https://dx.doi.org/10.33889/IJMEMS.2017.2.2-010

the economic order quantity model framework with random supply. Chang and Ho (2010) revisited the work of Wee et al. (2007) by applying renewal reward theorem in order to obtain the expected profit per unit time for their model.

Out of many factors, deterioration is one such factor, which should not be ignored, because the inventory level depletes not only because of demand but also due to deterioration. The inventory value depends upon the value of the product at the time of evaluation. Usually, deterioration can be explained in terms of spoilage, decay, damage, obsolescence, evaporation, pilferage, etc. which not only makes inventory holding tedious but also decreases the utility of the original product. When we talk about items such as hardware, glassware, steel and toys, the deterioration rate is not rapid; and there is slight requirement for considering deterioration in the determination of economic order quantity. However, some items like food and pharmaceuticals, chemicals, blood, alcohol, gasoline and other radioactive chemicals deteriorate at a rapid rate over time. For such products it is crucial to consider deterioration for a realistic inventory modeling. At first, Ghare and Scharader (1963) presented an EOQ model for deteriorating items which assumed decay to be exponential. Covert and Philip (1973) extended the model by assuming Weibull distribution deterioration. Afterwards, several interesting papers related to deterioration appeared in a couple of journals such as Dave and Patel (1981), Hollter and Mak (1983), Sachan (1984) etc. which were summarized by Raafat et al. (1991). Chung and Ting (1994), Hariga and Benkherouf (1994) also contributed in the field of deterioration. Jaggi et al. (2013a) developed a model for imperfect quality and deteriorating items with time dependent demand with inflation.

Further, it is a tacit assumption that payment to the supplier is done immediately for the purchased goods but in practical scenarios it is seen that a certain fixed credit period is given to the buyer for the settlement of the accounts. During this credit period no interest is charged but beyond this period interest will be payable under certain terms and conditions on which the two parties agreed upon. Prior to the settlement of the account, the buyer can sell the goods and earn revenue along with interest which can be regarded as a return on investment. Therefore, in terms of monetary benefits it is worthwhile for the buyer to delay the settlement of the account till the final day of the credit period allotted by the supplier. Kingsman (1983) investigated the effects of payment conditions for the economic order quantity model and claimed that the new model will fit the realistic scenario better. Goyal (1985), Davis and Gaither (1985) proposed optimal ordering policies for extended payment privileges for firms that are offered a one-time perk to delay their payment. Aggarwal and Jaggi (1995) extended Goyal (1985) model by putting forth the idea that if the credit period is less than the length of cycle, the customer will continue accumulating the revenue and interest earnings on it for the remaining period in the cycle, from the stock left after the credit period. Chu et al. (1998) considered deteriorating items under permissible delay in payments and proved the piecewise convexity of the total cost function of Aggarwal and Jaggi (1995). Thereafter, numerous research papers appeared in various journals, which were summarized by Soni et al. (2010).

In all of the aforementioned models, it is assumed that backorders are not allowed. Never-the less, in realistic scenarios, stock outs cannot be avoided due to uncertainties in demand and supply. Thus, in practical dealing it is essential to allow for shortages in an inventory system. Hariga (1995) and Chakrabarti and Chaudhari (1997) developed models for deteriorating items with time-varying and linear trend in demand. Wee et al. (2007) developed optimal inventory model for items with imperfect quality and shortage backordering. Chang and Ho (2010) considered imperfect quality items and shortage backordering, and obtained closed-form expressions. Further, Jaggi et al. (2013b) discussed economic ordering policies for defective items with shortages and trade-credit. 
Recently, Khanna et al. (2016) developed a model for deteriorating imperfect quality items with allowable shortages and permissible delay in payments.

Furthermore, in most of the economic production quantity (EPQ) models with the objective to maximize profit, researchers assumed demand to be constant. This assumption however does not hold in practice. Relationship between the demand and price is possibly one of the most basic concept of any supply chain. The theory about demand says that, if all other factors are set at a constant level, the increase in price will ultimately decrease the quantity demanded. Hence the price of the product plays a prominent role in the market. Therefore, it is reasonable to consider the demand as selling price dependent, as high selling price usually makes a negative impact on a major portion of buyers to purchase the goods. Consequently, demand is supposed to be inversely related to the selling price. In the current literature of inventory management, various forms of demand (like constant demand, price dependent demand etc.) have been studied by (Cohen, 1977; Aggarwal and Jaggi, 1989; Wee, 1997, 1999; Mukhopadhyay et al., 2004; Lin and Lin, 2015) and many more.

In view of the above mentioned facts and their significance in inventory modeling the present paper aims at investigating the problem of a retailer who has to manage items of imperfect quality which are also sensitive to deterioration. The demand is considered to be a function of selling price. Shortages are allowed and completely backlogged. The model considers trade credit so as to influence new customers and boost sales with the prime objective to increase the expected total profit of the retailer. Numerical analysis and Sensitivity analysis is performed so as to cater some important managerial inferences.

\section{Assumptions and Notations}

Following are the key assumptions that have been used to formulate the model:

(i) The demand is considered to be a selling price dependent i.e. $D(p)=k p^{-e}$, for simplicity $D(p)$ and $D$ will be used interchangeably.

(ii) The screening rate is assumed to be much higher than the demand rate, $\lambda>D$.

(iii) A random proportion of defective items, $\alpha$, with a known p.d.f. $f(\alpha)$, is present in the lot.

(iv) Shortages are allowed.

(v) A constant fraction $\theta$ of the inventory in hand deteriorates per unit time.

(vi) The defective items are independent of deterioration.

(vii) A fixed credit period $M$ is offered by the supplier to the retailer for the settlement of accounts.

Following is the set of notations that have been used in this model:

\begin{tabular}{ll}
\hline$K$ & ordering cost \\
$c$ & retailer's unit cost \\
$h$ & holding cost per unit time \\
$\theta$ & proportion of the on-and inventory lost due to deterioration \\
$\alpha$ & average proportion of defectives \\
$\lambda$ & rate of screening in units per unit time \\
$\beta$ & screening cost per unit \\
$t_{s}$ & screening time \\
$Q$ & order quantity \\
\hline
\end{tabular}


International Journal of Mathematical, Engineering and Management Sciences

Vol. 2, No. 2, 110-124, 2017

https://dx.doi.org/10.33889/IJMEMS.2017.2.2-010

\begin{tabular}{cl}
\hline$T$ & cycle length \\
$D$ & rate of demand per unit time $D(p)=k p^{-e}$ \\
$I_{e}$ & interest earned \\
$I_{p}$ & interest paid \\
$b$ & maximum backorder level allowed \\
$p$ & selling price per unit \\
$f(\alpha)$ & probability density function of percentage defectives $\alpha$ \\
$E(\alpha)$ & expected value of $\alpha, \int_{a}^{b} \alpha f(\alpha) d \alpha, 0<a<b<1$ \\
$M$ & credit period offered \\
$C_{2}$ & shortage cost \\
$I_{1}(t)$ & the level of inventory during the time interval $\left(0, t_{s}\right)$ \\
$I_{2}(t)$ & the level of inventory during the time interval $\left(t_{s}, t_{1}\right)$ \\
\hline
\end{tabular}

\section{Mathematical Model}

An inventory scenario is contemplated with an order quantity $Q$ which is delivered instantaneously to a retailer, with a unit cost $c$ and an ordering cost $K$. Every received lot contains a random proportion of defective items, $\alpha$, with a known probability density function $f(\alpha)$. After receiving each lot, a $100 \%$ screening is performed at a rate $\lambda$ per unit time. The defective items found after the screening process are kept in stock and sold at the end of the cycle as a single batch at a reduced price of $C_{s}$ per unit, where $\left(C_{s}<c\right)$. The demand $D$ of a product is considered to be a function of selling price $p$ i.e. $D(p)=D=k p^{-e}, \theta$ is the proportion of the inventory in hand which is lost per unit time because of deterioration, $t_{s}$ the screening time per cycle, $t_{s}=\frac{Q}{\lambda}$, and $T$ the cycle length. It is assumed that the backlogged demand is satisfied just after the completion of screening process. And, let $b$ be the backorder level, and $t_{2}$ the time to build a backorder level of $b$ units at the rate $D$, $t_{2}=\frac{b}{D}$. During time interval $\left(0, t_{s}\right)$ the inventory level, $I_{1}(t)$ decreases because of the combined effect of demand and deterioration. During time $t_{s}$, screening is performed and the inventory level gets reduced by the expected number of defectives found in the lot, $\alpha Q$ and by backorders, $b$, the backordered demand which is fulfilled from the inventory. During the time interval $\left(t_{s}, t_{1}\right)$, the inventory level $I_{2}(t)$ decreases due to demand and deterioration, and reaches zero at time $t_{1}$. Thereafter, the backorders starts to accumulate at the rate of $D$ units per unit time, until the beginning of a new cycle. After receiving the new lot size of $Q$ units, the screening process is initiated. The backordered demand is satisfied only after the screening of the new lot is completed till time $t_{s}$. Fig. 1 shows the inventory level over time for the retailer.

Let $I_{1}(t)$ be the inventory level at time $\left(0 \leq t \leq t_{s}\right)$.

Differential Equation for period, $\left(0, t_{s}\right)$ is given by:

$$
\frac{d I_{1}(t)}{d t}+\theta I_{1}(t)=-D(p)=-k p^{-e}=-D, \quad 0 \leq t \leq t_{s}
$$

The solution of the above differential equation along with the boundary condition, $t=0, I_{1}(0)=$ $Q$ is,

$I_{1}(t)=\frac{D}{\theta}\left(e^{-\theta t}-1\right)+Q e^{-\theta t}$ 
International Journal of Mathematical, Engineering and Management Sciences

Vol. 2, No. 2, 110-124, 2017

https://dx.doi.org/10.33889/IJMEMS.2017.2.2-010

After the screening process, the inventory level also drops by the number of defectives, $\alpha Q$ and the backorders, $b$.

Therefore, the effective inventory at $t=t_{s}$, after the removal of defectives and backorders is given by:

$I_{e f f .\left(t_{s}\right)}=Q e^{-\theta t_{s}}+\frac{D}{\theta}\left(e^{-\theta t_{s}}-1\right)-\alpha Q-b$

Now, let $I_{2}(t)$ be the inventory level at any time $\left(t_{s} \leq t \leq t_{1}\right)$.

Differential equation for period $\left(t_{s}, t_{1}\right)$ is given by:

$\frac{d I_{2}(t)}{d t}+\theta I_{2}(t)=-D(p)=-k p^{-e}=-D, t_{s} \leq t \leq t_{1}$

The solution of the above differential equation with boundary condition, $t=t_{s}, I_{2}\left(t_{s}\right)=I_{\text {eff. }}\left(t_{s}\right)$ is given by:

$I_{2}(t)=\frac{D}{\theta}\left(e^{-\theta t}-1\right)+Q e^{-\theta t}-\alpha Q e^{\theta\left(t_{s}-t\right)}-b e^{\theta\left(t_{s}-t\right)}$

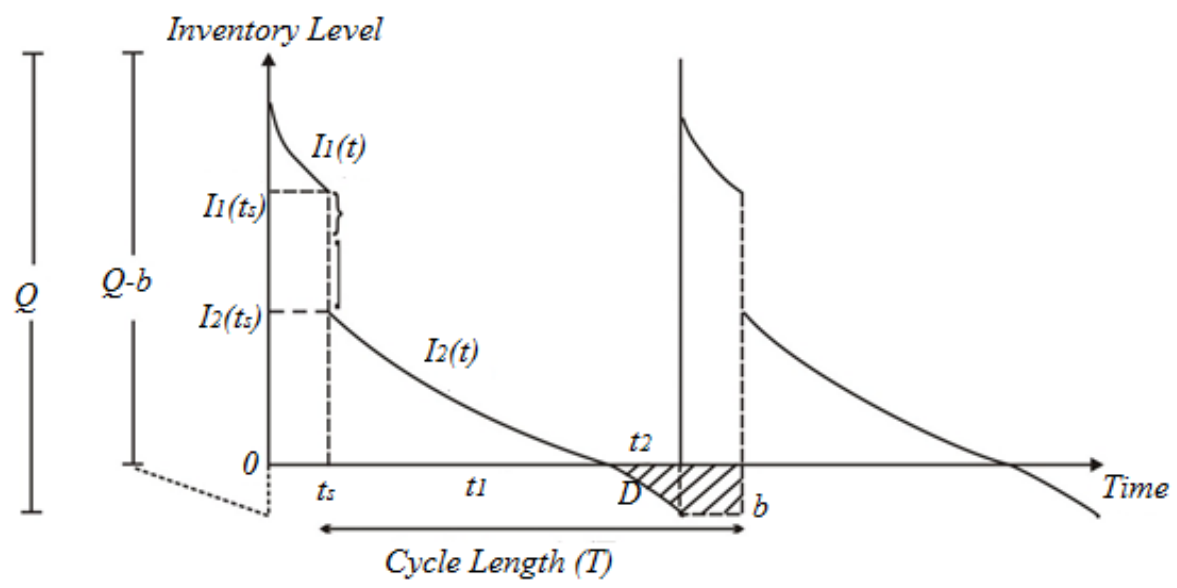

Fig. 1. Graphical representation of inventory level over time $T$

We will solve the equation for $t_{1}$ with condition $t=t_{1},\left(I_{2}\right) t_{1}=0$

$t_{1}=\frac{1}{\theta}\left[\log \left(\frac{D}{\theta}+Q-\alpha Q e^{\theta t_{s}}-\mu B e^{\theta t_{s}}\right)-\log \left(\frac{D}{\theta}\right)\right]$

$T=t_{1}+t_{2}$

where, $t_{2}=\frac{b}{D}$.

The present model also assumes the permissible delay in payments, therefore, subject to the credit period, three distinct possible cases (see Fig. 2) will rise for retailer's total profit $\pi_{j}, j=1,2,3, v i z$.

Case 1: $0 \leq M \leq t_{s}$

Case 2: $t_{s} \leq M \leq t_{1}$

Case 3: $t_{1} \leq M \leq T$ 
International Journal of Mathematical, Engineering and Management Sciences

Vol. 2, No. 2, 110-124, 2017

https://dx.doi.org/10.33889/IJMEMS.2017.2.2-010

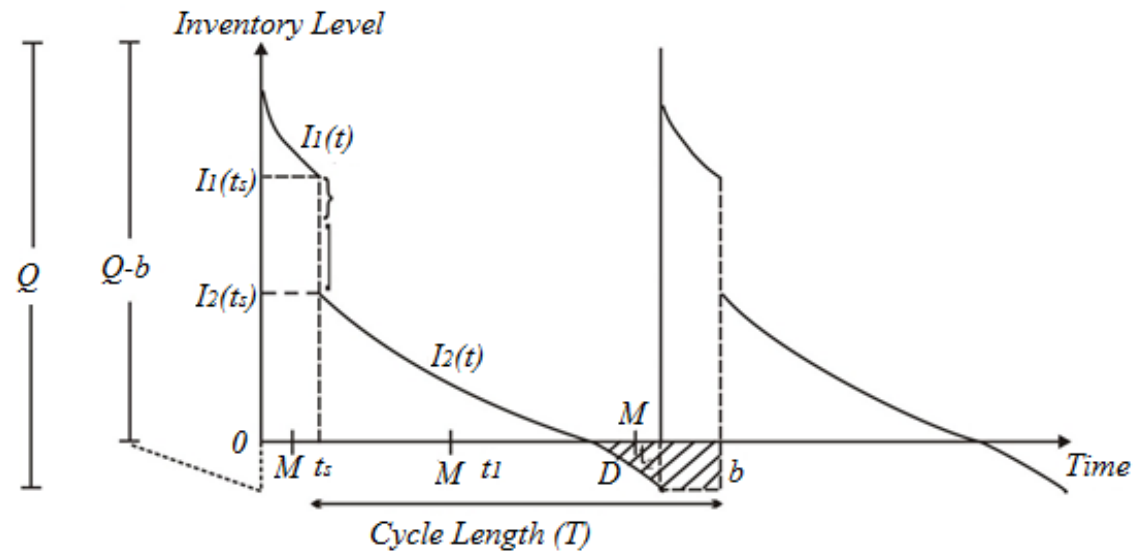

Fig. 2. Graphical representation of inventory system over time $T$

Since, the retailer's total profit is given by the equation as follows:

$\pi_{j}=$ Sales Revenue - Ordering cost - Screening Cost - Purchase cost - Holding Cost -

shortage cost + Interest Earned - Interest Paid

The components of equation (8) are evaluated as follows:

(a) Total sales revenue is obtained by adding the revenue generated by the demand met during e time period $(0, T)$ and sale of imperfect quality items $=p(1-\alpha) Q+C_{S} \alpha Q$

(b) Ordering cost $=K$

(c) Screening cost $=\beta Q$

(d) Shortage cost $=C_{2} b\left(t_{2}+2 t_{s}\right)$, where $b$ is the maximum permissible shortage.

(e) Purchase cost $=c Q$

(f) Holding cost for the time period 0 to $t_{s}$ and $t_{s}$ to $t_{1}$

$=h\left[\int_{0}^{t_{s}} I_{1}(t) d t+\int_{t_{s}}^{t_{1}} I_{2}(t) d t\right]$

$$
\begin{aligned}
= & h\left[\left[\frac{D}{\theta}\left(\frac{-1}{\theta}\left(e^{-\theta t_{s}}-1\right)-t_{s}\right)-Q\left(\frac{1}{\theta}\left(e^{-\theta t_{s}}-1\right)\right]+\left[\frac{D}{\theta}\left(\frac{-1}{\theta}\left(e^{-\theta t_{1}}-e^{-\theta t_{s}}\right)-\left(t_{1}-t_{s}\right)\right)-\right.\right.\right. \\
& \left.\left.\frac{Q}{\theta}\left(e^{-\theta t_{1}}-e^{-\theta t_{s}}\right)-\frac{\alpha Q}{\theta}\left(1-e^{\theta\left(t_{s}-t_{1}\right)}\right)-\frac{b}{\theta}\left(1-e^{\theta\left(t_{s}-t_{1}\right)}\right)\right]\right]
\end{aligned}
$$

To determine interest earned and payable, following three cases are considered:

Case 1: $0 \leq M \leq t_{s}$

In the present case, interest can be earned on revenue generated from the sales up to credit period $M$. However, one has to settle the account at $M$, which requires arranging money at some identified rate of interest so as to get the remaining stocks financed for the time period starting from $M$ to $T$.

2. Interest Earned $=p I_{e} \int_{0}^{M} D t d t$

$=p I_{e} \frac{D M^{2}}{2}$

3. Interest payable $=c I_{p}\left[\int_{M}^{t_{s}} I_{1}(t) d t+\int_{t_{s}}^{t_{1}} I_{2}(t) d t\right]$ 
International Journal of Mathematical, Engineering and Management Sciences

Vol. 2, No. 2, 110-124, 2017

https://dx.doi.org/10.33889/IJMEMS.2017.2.2-010

$$
\begin{aligned}
=c I_{p} & {\left[\begin{array}{c}
\frac{D}{\theta}\left(\frac{-1}{\theta}\left(e^{-\theta t_{s}}-e^{-\theta M}\right)-\left(t_{s}-M\right)\right)- \\
\frac{Q}{\theta}\left(e^{-\theta t_{s}}-e^{-\theta M}\right)
\end{array}\right\}+\left\{\frac{D}{\theta}\left(\frac{-1}{\theta}\left(e^{-\theta t_{1}}-e^{-\theta t_{s}}\right)-\left(t_{1}-t_{s}\right)\right)-\right.} \\
& \left.\left.\frac{Q}{\theta}\left(e^{-\theta t_{1}}-e^{-\theta t_{s}}\right)-\frac{\alpha Q}{\theta}\left(1-e^{\theta\left(t_{s}-t_{1}\right)}\right)-\frac{b}{\theta}\left(1-e^{\theta\left(t_{s}-t_{1}\right)}\right)\right\}\right]
\end{aligned}
$$

Substitute the values from Equations (9)-(16) in Equation (8), the total profit for case 1, $\pi_{1}(p, Q, B)$ becomes

$$
\begin{aligned}
& \pi_{1}(p, Q, B)=p(1-\alpha) Q+C_{s} \alpha Q-K-\beta Q-C_{2} b\left(t_{2}+2 t_{s}\right)-c Q-h\left[\left[\frac { D } { \theta } \left(\frac{-1}{\theta}\left(e^{-\theta t_{s}}-1\right)-\right.\right.\right. \\
& \left.t_{s}\right)-Q\left(\frac{1}{\theta}\left(e^{-\theta t_{s}}-1\right)\right]+\left[\frac{D}{\theta}\left(\frac{-1}{\theta}\left(e^{-\theta t_{1}}-e^{-\theta t_{s}}\right)-\left(t_{1}-t_{s}\right)\right)-\frac{Q}{\theta}\left(e^{-\theta t_{1}}-e^{-\theta t_{s}}\right)-\frac{\alpha Q}{\theta}(1-\right. \\
& \left.\left.\left.e^{\theta\left(t_{s}-t_{1}\right)}\right)-\frac{b}{\theta}\left(1-e^{\theta\left(t_{s}-t_{1}\right)}\right)\right]\right]+p I_{e} \frac{D M^{2}}{2}-c I_{p}\left[\begin{array}{c}
\frac{D}{\theta}\left(\frac{-1}{\theta}\left(e^{-\theta t_{s}}-e^{-\theta M}\right)-\left(t_{s}-M\right)\right)- \\
\frac{Q}{\theta}\left(e^{-\theta t_{s}}-e^{-\theta M}\right)
\end{array}\right\}+ \\
& \left\{\frac{D}{\theta}\left(\frac{-1}{\theta}\left(e^{-\theta t_{1}}-e^{-\theta t_{s}}\right)-\left(t_{1}-t_{s}\right)\right)-\frac{Q}{\theta}\left(e^{-\theta t_{1}}-e^{-\theta t_{s}}\right)-\frac{\alpha Q}{\theta}\left(1-e^{\theta\left(t_{s}-t_{1}\right)}\right)-\frac{b}{\theta}(1-\right.
\end{aligned}
$$

Case 2: $t_{s} \leq M \leq t_{1}$

In this particular case, revenue is generated from the sales up to credit period $M$ on which one can earn interest, one will also earn interest for the shortages which are met during $\left(M-t_{s}\right)$ and due to the sale of defective items during $\left(M-t_{s}\right)$.

4. Interest Earned $=p I_{e}\left[\int_{0}^{M} D t d t+b\left[\left(M-t_{s}\right)\right]+C_{s} \alpha Q I_{e}\left(M-t_{s}\right)\right.$

$$
=p I_{e}\left[\frac{D M^{2}}{2}+b\left(M-t_{s}\right)\right]+C_{s} \alpha Q I_{e}\left(M-t_{s}\right.
$$

5. Interest payable $=c I_{p}\left[\int_{M}^{t_{1}} I_{2}(t) d t\right]$

$$
\begin{aligned}
= & c I_{p}\left[\frac{D}{\theta}\left(\frac{-1}{\theta}\left(e^{-\theta t_{1}}-e^{-\theta M}\right)-\left(t_{1}-M\right)\right)-\frac{Q}{\theta}\left(e^{-\theta t_{1}}-e^{-\theta M}\right)-\frac{\alpha Q}{\theta}\left(1-e^{\theta\left(M-t_{1}\right)}\right)-\right. \\
& \left.\frac{b}{\theta}\left(1-e^{\theta\left(M-t_{1}\right)}\right)\right]
\end{aligned}
$$

Substitute the values from Equations (9)-(14), (18) and (19) in Equation (8), the total profit for case $\mathbf{2}, \pi_{2}(p, Q, B)$ becomes

$$
\begin{aligned}
& \pi_{2}(p, Q, B)=p(1-\alpha) Q+C_{s} \alpha Q-K-\beta Q-C_{2} b\left(t_{2}+2 t_{s}\right)-c Q-h\left[\left[\frac { D } { \theta } \left(\frac{-1}{\theta}\left(e^{-\theta t_{s}}-1\right)-\right.\right.\right. \\
& \left.\left.t_{s}\right)-Q\left(\frac{1}{\theta}\left(e^{-\theta t_{s}}-1\right)\right)\right]+\left[\frac{D}{\theta}\left(\frac{-1}{\theta}\left(e^{-\theta t_{1}}-e^{-\theta t_{s}}\right)-\left(t_{1}-t_{s}\right)\right)-\frac{Q}{\theta}\left(e^{-\theta t_{1}}-e^{-\theta t_{s}}\right)-\frac{\alpha Q}{\theta}(1-\right. \\
& \left.\left.\left.e^{\theta\left(t_{s}-t_{1}\right)}\right)-\frac{b}{\theta}\left(1-e^{\theta\left(t_{s}-t_{1}\right)}\right)\right]\right]+p I_{e}\left[\frac{D M^{2}}{2}+C_{B}\left(M-t_{s}\right)\right]+C_{s} \alpha Q I_{e}\left(M-t_{s}\right)-
\end{aligned}
$$


International Journal of Mathematical, Engineering and Management Sciences

Vol. 2, No. 2, 110-124, 2017

https://dx.doi.org/10.33889/IJMEMS.2017.2.2-010

$C I_{p}\left[\frac{D}{\theta}\left(\frac{-1}{\theta}\left(e^{-\theta t_{1}}-e^{-\theta M}\right)-\left(t_{1}-M\right)\right)-\frac{Q}{\theta}\left(e^{-\theta t_{1}}-e^{-\theta M}\right)-\frac{\alpha Q}{\theta}\left(1-e^{\theta\left(M-t_{1}\right)}\right)-\frac{b}{\theta}(1-\right.$
$\left.\left.e^{\theta\left(M-t_{1}\right)}\right)\right]$

Case 3: $t_{1} \leq M \leq T$

This particular case depicts the situation in which inventory cycle is less than or equal to credit period. Thus, here no interest is paid by the retailer. However, in addition to the interest earned in the above case, the retailer also earns interest on the whole revenue generated by demand, for the time period $\left(M-t_{1}\right)$

5. Interest Earned $=p I_{e} \int_{0}^{t_{1}} D t d t+p I_{e}\left[D t_{1}\right]\left[M-t_{1}\right]+p I_{e} b\left[M-t_{s}\right]+C_{s} \alpha Q I_{e}\left[M-t_{s}\right]$

$$
=p I_{e}\left(\left(\frac{D t_{1}{ }^{2}}{2}\right)+\left[D t_{1}\right]\left[M-t_{1}\right]+b\left[M-t_{s}\right]\right)+C_{s} \alpha Q I_{e}\left[M-t_{s}\right]
$$

6. Interest Payable $=0$

Substitute the values from Equations (9)-(14), (21) and (22) in Equation (8), the total profit for Case 3, $\pi_{3}(p, Q, B)$ becomes

$$
\begin{aligned}
& \pi_{3}(p, Q, B)=p(1-\alpha) Q+C_{s} \alpha Q-K-\beta Q-C_{2} b\left(t_{2}+2 t_{s}\right)-c Q-h\left[\left[\frac { D } { \theta } \left(\frac{-1}{\theta}\left(e^{-\theta t_{s}}-1\right)-\right.\right.\right. \\
& \left.\left.t_{s}\right)-Q\left(\frac{1}{\theta}\left(e^{-\theta t_{s}}-1\right)\right)\right]+\left[\frac{D}{\theta}\left(\frac{-1}{\theta}\left(e^{-\theta t_{1}}-e^{-\theta t_{s}}\right)-\left(t_{1}-t_{s}\right)\right)-\frac{Q}{\theta}\left(e^{-\theta t_{1}}-e^{-\theta t_{s}}\right)-\frac{\alpha Q}{\theta}(1-\right. \\
& \left.\left.\left.e^{\theta\left(t_{s}-t_{1}\right)}\right)-\frac{b}{\theta}\left(1-e^{\theta\left(t_{s}-t_{1}\right)}\right)\right]\right]+p I_{e}\left(\left(\frac{D t_{1}{ }^{2}}{2}\right)+\left[D t_{1}\right]\left[M-t_{1}\right]+b\left[M-t_{s}\right]\right)+C_{s} \alpha Q I_{e}[M- \\
& t_{s}
\end{aligned}
$$

Case 4: $T \leq M$

In the present scenario, all the expressions for the interest earned and payable coincide with that of previous case.

Hence, the following three different cases for the retailer's total profit per cycle, $\pi(p, Q, B)$ arise, which are given below

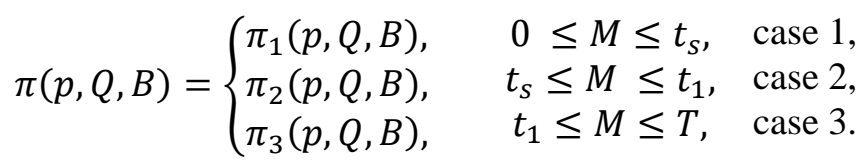

In order to find the expected total profit per unit time, renewal reward theorem Ross (1996) is applied, since $\alpha$ is considered to be a random variable whose probability density function, $f(\alpha)$ is known. Hence, the expected total profit per unit time for different cases can be obtained as follows:

$$
E\left[\pi^{T}(p, Q, B)\right]=E\left[\frac{\pi(p, Q, B)}{T}\right]=\frac{E[\pi(p, Q, B)]}{E[T]},
$$


International Journal of Mathematical, Engineering and Management Sciences

Vol. 2, No. 2, 110-124, 2017

https://dx.doi.org/10.33889/IJMEMS.2017.2.2-010

$$
\pi(p, Q, B)=\left\{\begin{array}{llll}
E\left[\pi_{1}^{T}(p, Q, B)\right]=E\left[\pi_{1}(p, Q, B)\right] / E[T], & 0 \leq M \leq t_{s}, & \text { case } 1, & \text { (26 a) } \\
E\left[\pi_{2}^{T}(p, Q, B)\right]=E\left[\pi_{2}(p, Q, B)\right] / E[T], & t_{s} \leq M \leq t_{1}, & \text { case } 2, & (26 \mathrm{~b}) \\
E\left[\pi_{3}^{T}(p, Q, B)\right]=E\left[\pi_{3}(p, Q, B)\right] / E[T] . & t_{1} \leq M \leq T, & \text { case 3, } & \text { (26 c) }
\end{array}\right.
$$

where,

$$
\begin{aligned}
& E\left[\pi_{1}(p, Q, B)\right]=p(1-E[\alpha]) Q+C_{S} E[\alpha] Q-K-\beta Q-C_{2} b\left(t_{2}+2 t_{s}\right)-c Q- \\
& h\left[\left[\frac{D}{\theta}\left(\frac{-1}{\theta}\left(e^{-\theta t_{s}}-1\right)-t_{s}\right)-Q\left(\frac{1}{\theta}\left(e^{-\theta t_{s}}-1\right)\right)\right]+\left[\frac{D}{\theta}\left(\frac{-1}{\theta}\left(e^{-\theta t_{1}}-e^{-\theta t_{s}}\right)-\left(t_{1}-t_{s}\right)\right)-\right.\right. \\
& \left.\left.\frac{Q}{\theta}\left(e^{-\theta t_{1}}-e^{-\theta t_{s}}\right)-\frac{E[\alpha] Q}{\theta}\left(1-e^{\theta\left(t_{s}-t_{1}\right)}\right)-\frac{b}{\theta}\left(1-e^{\theta\left(t_{s}-t_{1}\right)}\right)\right]\right]+p I_{e} \frac{D M^{2}}{2}- \\
& c I_{p}\left[\left\{\begin{array}{c}
\frac{D}{\theta}\left(\frac{-1}{\theta}\left(e^{-\theta t_{s}}-e^{-\theta M}\right)-\left(t_{s}-M\right)\right)- \\
\frac{Q}{\theta}\left(e^{-\theta t_{s}}-e^{-\theta M}\right)
\end{array}\right\}+\left\{\frac{D}{\theta}\left(\frac{-1}{\theta}\left(e^{-\theta t_{1}}-e^{-\theta t_{s}}\right)-\left(t_{1}-t_{s}\right)\right)-\right.\right. \\
& \left.\left.\frac{Q}{\theta}\left(e^{-\theta t_{1}}-e^{-\theta t_{s}}\right)-\frac{E[\alpha] Q}{\theta}\left(1-e^{\theta\left(t_{s}-t_{1}\right)}\right)-\frac{b}{\theta}\left(1-e^{\theta\left(t_{s}-t_{1}\right)}\right)\right\}\right] \\
& E\left[\pi_{2}(p, Q, B)\right]=p(1-E[\alpha]) Q+C_{s} E[\alpha] Q-K-\beta Q-C_{2} b\left(t_{2}+2 t_{s}\right)-c Q- \\
& h\left[\left[\frac{D}{\theta}\left(\frac{-1}{\theta}\left(e^{-\theta t_{s}}-1\right)-t_{s}\right)-Q\left(\frac{1}{\theta}\left(e^{-\theta t_{s}}-1\right)\right)\right]+\left[\frac{D}{\theta}\left(\frac{-1}{\theta}\left(e^{-\theta t_{1}}-e^{-\theta t_{s}}\right)-\left(t_{1}-t_{s}\right)\right)-\right.\right. \\
& \left.\left.\frac{Q}{\theta}\left(e^{-\theta t_{1}}-e^{-\theta t_{s}}\right)-\frac{E[\alpha] Q}{\theta}\left(1-e^{\theta\left(t_{s}-t_{1}\right)}\right)-\frac{b}{\theta}\left(1-e^{\theta\left(t_{s}-t_{1}\right)}\right)\right]\right]+p I_{e}\left[\frac{D M^{2}}{2}+b\left(M-t_{s}\right)\right]+ \\
& C_{s} E[\alpha] Q I_{e}\left(M-t_{s}\right)-c I_{p}\left[\frac{D}{\theta}\left(\frac{-1}{\theta}\left(e^{-\theta t_{1}}-e^{-\theta M}\right)-\left(t_{1}-M\right)\right)-\frac{Q}{\theta}\left(e^{-\theta t_{1}}-e^{-\theta M}\right)-\right. \\
& \left.\frac{E[\alpha] Q}{\theta}\left(1-e^{\theta\left(M-t_{1}\right)}\right)-\frac{b}{\theta}\left(1-e^{\theta\left(M-t_{1}\right)}\right)\right] \\
& E\left[\pi_{3}(p, Q, B)\right]=p(1-E[\alpha]) Q+C_{s} E[\alpha] Q-K-\beta Q-C_{2} b\left(t_{2}+2 t_{s}\right)-c Q- \\
& h\left[\left[\frac{D}{\theta}\left(\frac{-1}{\theta}\left(e^{-\theta t_{s}}-1\right)-t_{s}\right)-Q\left(\frac{1}{\theta}\left(e^{-\theta t_{s}}-1\right)\right)\right]+\left[\frac{D}{\theta}\left(\frac{-1}{\theta}\left(e^{-\theta t_{1}}-e^{-\theta t_{s}}\right)-\left(t_{1}-t_{s}\right)\right)-\right.\right. \\
& \left.\left.\frac{Q}{\theta}\left(e^{-\theta t_{1}}-e^{-\theta t_{s}}\right)-\frac{E[\alpha] Q}{\theta}\left(1-e^{\theta\left(t_{s}-t_{1}\right)}\right)-\frac{b}{\theta}\left(1-e^{\theta\left(t_{s}-t_{1}\right)}\right)\right]\right]+p I_{e}\left(\left(\frac{D t_{1}{ }^{2}}{2}\right)+\left[D t_{1}\right][M-\right. \\
& \left.\left.t_{1}\right]+b\left[M-t_{s}\right]\right)+C_{s} E[\alpha] Q I_{e}\left[M-t_{s}\right] \\
& \text { and }, E[T]=\frac{(1-E[\alpha]) Q}{D} \cdot
\end{aligned}
$$

\section{Solution Procedure}

The objective of the model is to determine the optimal values of $Q, b$, and $p$ which results in maximization of the total profit function, $\left[\pi_{i}^{T}(Q, b, p)\right] \mathrm{i}=1,2,3$. Hence, the necessary conditions for optimality are

$$
\begin{aligned}
& \frac{\partial E\left[\pi_{i}^{T}(Q, b, p)\right]}{\partial Q}=0, \\
& \frac{\partial E\left[\pi_{i}^{T}(Q, b, p)\right]}{\partial b}=0, \text { and }
\end{aligned}
$$


International Journal of Mathematical, Engineering and Management Sciences

Vol. 2, No. 2, 110-124, 2017

https://dx.doi.org/10.33889/IJMEMS.2017.2.2-010

$\frac{\partial E\left[\pi_{i}^{T}(Q, b, p)\right]}{\partial p}=0$

The sufficient conditions in order to maximize the profit function are $D_{1}(Q, b, p)<0$, $D_{2}(Q, b, p)>0$, and $D_{3}(Q, b, p)<0$. By using the Hessian matrix $H$ (matrix of second order partial derivatives) we have,

$H=\left[\begin{array}{lll}\frac{\partial^{2} E\left[\pi^{T}(Q, b, p)\right]}{\partial Q^{2}} & \frac{\partial^{2} E\left[\pi^{T}(Q, b, p)\right]}{\partial Q \partial b} & \frac{\partial^{2} E\left[\pi^{T}(Q, b, p)\right]}{\partial Q \partial p} \\ \frac{\partial^{2} E\left[\pi^{T}(Q, b, p)\right]}{\partial b \partial Q} & \frac{\partial^{2} E\left[\pi^{T}(Q, b, p)\right]}{\partial b^{2}} & \frac{\partial^{2} E\left[\pi^{T}(Q, b, p)\right]}{\partial b \partial p} \\ \frac{\partial^{2} E\left[\pi^{T}(Q, b, p)\right]}{\partial p \partial Q} & \frac{\partial^{2} E\left[\pi^{T}(Q, b, p)\right]}{\partial p \partial b} & \frac{\partial^{2} E\left[\pi^{T}(Q, b, p)\right]}{\partial p^{2}}\end{array}\right], D_{1}=\frac{\partial^{2} E\left[\pi^{T}(Q, b, p)\right]}{\partial Q^{2}}$,
$D_{2}=\left[\begin{array}{lll}\frac{\partial^{2} E\left[\pi^{T}(Q, b, p)\right]}{\partial Q^{2}} & \frac{\partial^{2} E\left[\pi^{T}(Q, b, p)\right]}{\partial Q \partial b} \\ \frac{\partial^{2} E\left[\pi^{T}(Q, b, p)\right]}{\partial b \partial Q} & \frac{\partial^{2} E\left[\pi^{T}(Q, b, p)\right]}{\partial b^{2}}\end{array}\right]$,
$D_{3}=\operatorname{det} H=\left[\begin{array}{lll}\frac{\partial^{2} E\left[\pi^{T}(Q, b, p)\right]}{\partial Q^{2}} & \frac{\partial^{2} E\left[\pi^{T}(Q, b, p)\right]}{\partial Q \partial b} & \frac{\partial^{2} E\left[\pi^{T}(Q, b, p)\right]}{\partial Q \partial p} \\ \frac{\partial^{2} E\left[\pi^{T}(Q, b, p)\right]}{\partial b \partial Q} & \frac{\partial^{2} E\left[\pi^{T}(Q, b, p)\right]}{\partial b^{2}} & \frac{\partial^{2} E\left[\pi^{T}(Q, b, p)\right]}{\partial b \partial p} \\ \frac{\partial^{2} E\left[\pi^{T}(Q, b, p)\right]}{\partial p \partial Q} & \frac{\partial^{2} E\left[\pi^{T}(Q, b, p)\right]}{\partial p \partial b} & \frac{\partial^{2} E\left[\pi^{T}(Q, b, p)\right]}{\partial p^{2}}\end{array}\right]$, where $D_{1}, D_{2}$, and $D_{3}$ are the minors

of the Hessian matrix $H$.

The profit functions obtained above are extremely non-linear therefore it gets complex to establish the concavity mathematically. Thus, the concavity has been established with the help of graphs (Fig. 3), using MAPLE.
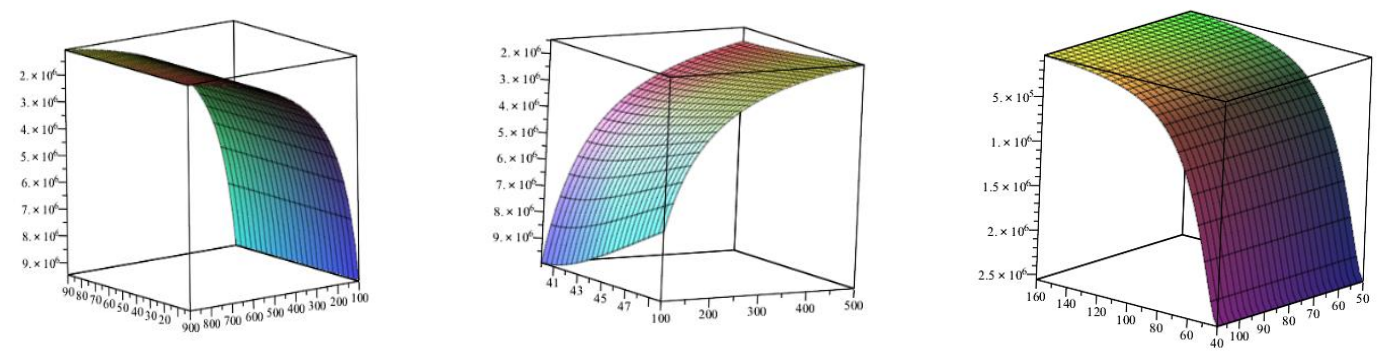

Fig. 3. Graphical representation of total profit function

\section{Algorithm}

Step 1. Determine $Q^{*}=Q_{1}$ (say) and $b=b_{1}$ (say), and $p=p_{1}$ from equation (30), (31) and (32) taking $i=1$. Now using the value of $Q, b$ and $p$ calculate the value of $t_{1}$ and $T$ from equation (6) and (7). If $0 \leq M \leq t_{s} \leq t_{1}$ the expected total profit can be obtained from equation (27) else set $E\left[\pi_{1}(Q, b, p)\right]=0$. 
International Journal of Mathematical, Engineering and Management Sciences

Vol. 2, No. 2, 110-124, 2017

https://dx.doi.org/10.33889/IJMEMS.2017.2.2-010

Step 2. Determine $Q^{*}=Q_{2}$ (say) and $b=b_{2}$ (say), and $p=p_{2}$ from equation (30), (31) and (32) taking $i=2$. Now using the value of $Q, b$ and $p$ calculate the value of $t_{1}$ and $T$ from equation (6) and (7). If $t_{s} \leq M \leq t_{1}$ the expected total profit can be obtained from equation (28) elseset $E\left[\pi_{2}(Q, b, p)\right]=0$.

Step 3. Determine $Q^{*}=Q_{3}$ (say) and $b=b_{3}$ (say), and $p=p_{3}$ from equation (30), (31) and (32) taking $i=3$. Now using the value of $Q, b$ and $p$ calculate the value of $t_{1}$ and $T$ from equation (6) and (7). If $t_{1} \leq M \leq T$ the expected total profit can be obtained from equation (29) else $\operatorname{set} E\left[\pi_{3}(Q, b, p)\right]=0$.

Step 4. Compare the calculated expected profit for case 1, 2, and 3 and select the optimal values of $Q, b$ and $p$ associated with the maximum expected profit.

\section{Numerical Analysis}

Example 1. An example is devised to validate the model with the following data.

$K=\$ 100$ per cycle, $c=\$ 25 /$ unit, $h=\$ 10 /$ unit/year, $\theta=0.05, \alpha=0.02, \lambda=175200$ units/year, $\beta=\$ 0.5 /$ unit,$M=0.001 \quad$ year, $I_{e}=0.10 /$ year, $\quad I_{p}=0.15 /$ year,$\quad C_{s}=\$ 20 /$ unit,$\quad C_{2}=\$ 5 /$ year, $k=500000000$, and $e=2.5$.

By applying the proposed algorithm results are obtained as follows: the optimal order level $Q^{*}=899.95$ units, the backorder level $b^{*}=283.97$ units, the selling price $p^{*}=42.94$ and the expected total profit $E\left[\pi^{T}(Q, b, p)\right]=\$ 707837$.

Example 2. An example is devised to validate the model with the following data.

$K=\$ 100$ per cycle, $c=\$ 25 /$ unit, $h=\$ 10 /$ unit/year, $\theta=0.05, \alpha=0.02, \lambda=175200$ units/year, $\beta=\$ 0.5 /$ unit,$M=0.018 \quad$ year, $I_{e}=0.10 /$ year, $\quad I_{p}=0.15 /$ year,$\quad C_{s}=\$ 20 /$ unit,$\quad C_{2}=\$ 5 /$ year , $k=500000000$, and $e=2.5$.

By applying the proposed algorithm results are obtained as follows: the optimal order level $Q^{*}=888.41$ units, the backorder level $b^{*}=288.24$ units, the selling price $p^{*}=42.85$ and the expected total profit $E\left[\pi^{T}(Q, b, p)\right]=\$ 710774$.

\section{Sensitivity Analysis}

In this section, sensitivity analysis is performed to study the effect of expected number of imperfect quality items $(\alpha)$, holding cost $(h)$, shortage cost $\left(C_{2}\right)$,permissible delay $(M)$ and price elasticity index $(e)$, on the lot size $\left(Q^{*}\right)$, backorders $\left(b^{*}\right)$ selling price $\left(p^{*}\right)$ and the expected total profit $\left(E\left[\pi^{T}\left(Q^{*}, b^{*}, p^{*}\right)\right]\right)$. Results have been given in Tables $1-4$.

\begin{tabular}{|c|c|c|c|c|l|}
\hline $\boldsymbol{\alpha}$ & $\boldsymbol{p}$ & $\boldsymbol{Q}$ & $\boldsymbol{b}$ & $\boldsymbol{D}$ & Profit \\
\hline 0.01 & 42.84 & 896.79 & 286.92 & 41605.63 & 710233 \\
\hline 0.02 & 42.94 & 900.01 & 284.00 & 41371.27 & 707837 \\
\hline 0.03 & 43.04 & 903.17 & 281.06 & 41134.08 & 705406 \\
\hline 0.04 & 43.14 & 906.45 & 278.24 & 40893.69 & 702938 \\
\hline
\end{tabular}

Table 1. Effect of changing the percentage of defectives on the selling price, optimal order level, backorder level, and retailer's expected profit 
International Journal of Mathematical, Engineering and Management Sciences

Vol. 2, No. 2, 110-124, 2017

https://dx.doi.org/10.33889/IJMEMS.2017.2.2-010

\begin{tabular}{|c|c|c|c|c|c|c|}
\hline $\boldsymbol{C}_{2}$ & $\boldsymbol{h}$ & $\boldsymbol{p}$ & $\boldsymbol{Q}$ & $\boldsymbol{b}$ & $\boldsymbol{D}$ & Profit \\
\hline & 5 & 42.88 & 1091.60 & 213.05 & 41505.54 & 709477 \\
\hline 5 & 10 & 42.94 & 900.01 & 284.00 & 41371.27 & 707837 \\
\hline & 15 & 42.98 & 795.65 & 312.64 & 41263.31 & 706617 \\
\hline & 5 & 42.87 & 1045.38 & 41.82 & 41543.92 & 709131 \\
\hline 10 & 10 & 42.93 & 838.38 & 123.83 & 41390.50 & 707146 \\
\hline & 15 & 42.98 & 732.39 & 166.26 & 41272.88 & 705701 \\
\hline & 5 & 42.86 & 1042.64 & 0 & 41567.97 & 709107 \\
\hline 15 & 10 & 42.92 & 819.06 & 47.50 & 41423.24 & 706904 \\
\hline & 15 & 42.97 & 706.83 & 92.10 & 41294.05 & 705283 \\
\hline
\end{tabular}

Table 2. Effect of changing the holding cost and shortage cost on the selling price, optimal order level, backorder level, and retailer's expected profit

\begin{tabular}{|c|c|c|c|c|l|}
\hline $\boldsymbol{M}$ & $\boldsymbol{p}$ & $\boldsymbol{Q}$ & $\boldsymbol{b}$ & $\boldsymbol{D}$ & Profit \\
\hline 3 & 42.89 & 894.00 & 285.00 & 41479.53 & 709170 \\
\hline 5 & 42.87 & 888.41 & 288.24 & 41547.22 & 710235 \\
\hline 7 & 42.85 & 888.41 & 288.24 & 41578.80 & 710774 \\
\hline
\end{tabular}

Table 3. Effect of changing permissible delay in paymentson the selling price, optimal order level, backorder level, and retailer's expected profit

\begin{tabular}{|c|c|c|c|c|l|}
\hline $\boldsymbol{e}$ & $\boldsymbol{p}$ & $\boldsymbol{Q}$ & $\boldsymbol{b}$ & $\boldsymbol{D}$ & Profit \\
\hline 2.0 & 51.35 & 1740.05 & 0 & 189615.80 & 4858962 \\
\hline 2.5 & 42.94 & 900.01 & 284.00 & 41371.27 & 707837 \\
\hline 3.0 & 38.77 & 507.11 & 256.92 & 8576.18 & 109472 \\
\hline 3.5 & 36.47 & 244.31 & 133.87 & 1706.35 & 17113 \\
\hline 4.0 & 35.44 & 107.17 & 59.67 & 316.80 & 2512 \\
\hline
\end{tabular}

Table 4. Effect of changing price elasticity index on the selling price, optimal order level, backorder level, and retailer's expected profit

\section{Observations}

- With increase in the percentage of defectives, the optimal order size tends to increase but the profit decreases. Since, an increase in number of defectives in the ordered lot implies salvaging more items at a discounted price, hence it results in lower profits.

- A trade-off can be observed between holding and shortage cost. With a rise in the holding cost, the backorder level increases and the optimal order level and the profit decreases. For such a scenario, it is suggested to stock less in the inventory and backorder more of the demand so as to avoid larger holding costs. However, for a fixed holding cost as the shortage cost increases, the order size, backorder size and retailer's expected profit decreases significantly. 
International Journal of Mathematical, Engineering and Management Sciences

Vol. 2, No. 2, 110-124, 2017

https://dx.doi.org/10.33889/IJMEMS.2017.2.2-010

- From Table 3 it is observed that with increase in the credit period there is a decrease in the price and the optimal order quantity. In such a scenario, it is advisable to order less quantity on a more regular basis in order to fetch the benefit of delay in payment. The rise in demand and the total profit implies the positive impact of trade-credit in the modeling.

- When the price elasticity index increases; the demand, price and retailer's expected total profit tends to decrease significantly. Since demand of the product has an inverse relationship with the price elasticity index so when the price elasticity increases, demand decreases resulting in lower profits for the organization.

\section{Conclusion}

In this paper, an inventory control model is developed for deteriorating imperfect quality items with allowable shortages under the condition of permissible delay in payments with price dependent demand. The notion of taking demand to be price sensitive places a premium on comprehending the buying behavior and the uniqueness of products or services in the marketplace. Considering the impact of imperfect-quality items is quite realistic, since the production process is not always perfect and may lead to defectives. Also, deterioration is natural phenomena that should not be ignored while talking about holding inventory. Further, trade-credit is a renowned business gimmick to elevate sales. Incorporating all the above concepts, an expression for the expected total profit of the retailer is derived, and the model is validated with the help of numerical examples. To establish the robustness of the model sensitivity analysis on key model parameters has also been presented. Findings of the numerical and sensitivity analysis provide some important managerial insights.

Further, future research can be done by extending the developed model for more practical situations such as stochastic and stock dependent demand with inflation, time varying holding costs etc.

\section{References}

Aggarwal, S. P., \& Jaggi, C. K. (1989). Ordering policy for decaying inventory. International Journal of Systems Science, 20(1), 151-155.

Aggarwal, S. P., \& Jaggi, C. K. (1995). Ordering policies of deteriorating items under permissible delay in payments. Journal of the Operational Research Society, 46(5), 658-662.

Chakrabarti, T., \& Chaudhuri, K. S. (1997). An EOQ model for deteriorating items with a linear trend in demand and shortages in all cycles. International Journal of Production Economics, 49(3), 205-213.

Chang, H. C., \& Ho, C. H. (2010). Exact closed-form solutions for optimal inventory model for items with imperfect quality and shortage backordering. Omega, 38(3), 233-237.

Chu, P., Chung, K. J., \& Lan, S. P. (1998). Economic order quantity of deteriorating items under permissible delay in payments. Computers \& Operations Research, 25(10), 817-824.

Chung, K. J., \& Ting, P. S. (1994). On replenishment schedule for deteriorating items with time-proportional demand. Production Planning \& Control, 5(4), 392-396.

Cohen, M. A. (1977). Joint pricing and ordering policy for exponentially decaying inventory with known demand. Naval Research Logistics Quarterly, 24(2), 257-268.

Covert, R. P., \& Philip, G. C. (1973). An EOQ model for items with Weibull distribution deterioration. AIIE Transactions, 5(4), 323-326. 
International Journal of Mathematical, Engineering and Management Sciences

Vol. 2, No. 2, 110-124, 2017

https://dx.doi.org/10.33889/IJMEMS.2017.2.2-010

Dave, U., \& Patel, L. K. (1981). (T, S i) policy inventory model for deteriorating items with time proportional demand. Journal of the Operational Research Society, 32(2), 137-142.

Davis, R. A., \& Gaither, N. (1985). Optimal ordering policies under conditions of extended payment privileges. Management Science, 31(4), 499-509.

Ghare, P. M., \& Schrader, G. F. (1963). A model for exponentially decaying inventory. Journal of Industrial Engineering, 14(5), 238-243.

Goyal, S. K. (1985). Economic order quantity under conditions of permissible delay in payments. Journal of the Operational Research Society, 36(4), 335-338.

Hariga, M. (1995). An EOQ model for deteriorating items with shortages and time-varying demand. Journal of the Operational Research Society, 46(3), 398-404.

Hariga, M. A., \& Benkherouf, L. (1994). Optimal and heuristic inventory replenishment models for deteriorating items with exponential time-varying demand. European Journal of Operational Research, 79(1), 123-137.

Hollter, R. H., \& Mak, K. L. (1983). Inventory replenishment policies for deteriorating items in a declining market. The International Journal of Production Research, 21(6), 813-836.

Jaggi, C. K., Goel, S. K., \& Mittal, M. (2013b). Credit financing in economic ordering policies for defective items with allowable shortages. Applied Mathematics and Computation, 219(10), 5268-5282.

Jaggi, C. K., Mittal, M., \& Khanna, A. (2013a). Effects of inspection on retailer's ordering policy for deteriorating items with time-dependent demand under inflationary conditions. International Journal of Systems Science, 44(9), 1774-1782.

Khanna, A., Mittal, M., Gautam, P., \& Jaggi, C. (2016). Credit financing for deteriorating imperfect quality items with allowable shortages. Decision Science Letters, 5(1), 45-60.

Kingsman, B. G. (1983). The effect of payment rules on ordering and stockholding in purchasing. Journal of the Operational Research Society, 34(11), 1085-1098.

Lee, H. L., \& Rosenblatt, M. J. (1987). Simultaneous determination of production cycle and inspection schedules in a production system. Management Science, 33(9), 1125-1136.

Lin, Y. J., \& Lin, H. J. (2015). Integrated Supply Chain Model with Price-dependent Demand and Product Recovery. Journal of Applied Science and Engineering, 18(3), 213-222.

Maddah, B., \& Jaber, M. Y. (2008). Economic order quantity for items with imperfect quality: revisited. International Journal of Production Economics, 112(2), 808-815.

Maddah, B., Moussawi, L., \& Jaber, M. Y. (2010). Lot sizing with a Markov production process and imperfect items scrapped. International Journal of Production Economics, 124(2), 340-347.

Mukhopadhyay, S., Mukherjee, R. N., \& Chaudhuri, K. S. (2004). Joint pricing and ordering policy for a deteriorating inventory. Computers \& Industrial Engineering, 47(4), 339-349.

Papachristos, S., \& Konstantaras, I. (2006). Economic ordering quantity models for items with imperfect quality. International Journal of Production Economics, 100(1), 148-154.

Porteus, E. L. (1986). Optimal lot sizing, process quality improvement and setup cost reduction. Operations Research, 34(1), 137-144.

Raafat, F. F., Wolfe, P. M., \& Eldin, H. K. (1991). An inventory model for deteriorating items. Computers \& Industrial Engineering, 20(1), 89-94.

Rosenblatt, M. J., \& Lee, H. L. (1986). Economic production cycles with imperfect production processes. IIE Transactions, 18(1), 48-55. 
International Journal of Mathematical, Engineering and Management Sciences

Vol. 2, No. 2, 110-124, 2017

https://dx.doi.org/10.33889/IJMEMS.2017.2.2-010

Ross, S. M. (1996). Stochastic processes (Vol. 2). New York: John Wiley \& Sons.

Sachan, R. S. (1984). On (T, S i) policy inventory model for deteriorating items with time proportional demand. Journal of the Operational Research Society, 35(11), 1013-1019.

Salameh, M. K., \& Jaber, M. Y. (2000). Economic production quantity model for items with imperfect quality. International Journal of Production Economics, 64(1), 59-64.

Soni, H., Shah, N. H., \& Jaggi, C. K. (2010). Inventory models and trade credit: a review. Control and Cybernetics, 39(3), 867-882.

Wee, H. M. (1997). A replenishment policy for items with a price-dependent demand and a varying rate of deterioration. Production Planning \& Control, 8(5), 494-499.

Wee, H. M. (1999). Deteriorating inventory model with quantity discount, pricing and partial backordering. International Journal of Production Economics, 59(1), 511-518.

Wee, H. M., Yu, J., \& Chen, M. C. (2007). Optimal inventory model for items with imperfect quality and shortage backordering. Omega, 35(1), 7-11. 